transportation and road safety agencies (including vehicle designers). One measure should include changing crash investigation processes to identify SUVs in vehicle-pedestrian impact statistics. Given the increasing economic importance of the SUV market to car manufacturers, traffic safety activists in the health professions will need to keep pressure on governments to make sure they don't put economic and industrial interests ahead of effective safety strategies. ${ }^{10}$

In the meantime, informing consumers of the increased risk to pedestrians from SUVs may represent a useful first step in raising public awareness. The Irish Medical Organisation has recently called on motor manufacturers and distributors to display warning notices on SUVs that advise potential purchasers of the increased risk of severe

1 Sklar DP, Demarest GB, McFeeley P. Increased pedestrian mortality among elderly. Am J Emergency Med 1989;7:387-90.

2 National Roads Authority. Road Accident Facts Ireland, 2000. Dublin National Roads Authority, 2000.

3 Hakamies-Blomqvist L, O'Neill D. Older people and road traffic injury. World Report on Traffic Injury Prevention. Geneva: WHO, 2004:47.

4 European Transport Safety Council. Reducing traffic injuries through vehicle safety improvements-the role of car design. Brussels: European Transport Safety Council, 1993.

5 Liu XJ, Yang JK, Lovsund P. A study of influences of vehicle speed and front structure on Pedestrian Impact Responses using mathematical front structure on Pedestrian Impact Resp

6 Lefler DE, Gabler HC. The fatality and injury risk of light truck impacts with pedestrians in the United States. Accid Anal Prev 2004;36:295-304 injury and death to pedestrians associated with these vehicles. Resistance from the industry to such initiatives is likely to be strong, just as it has been from the tobacco industry for warnings on cigarettes. ${ }^{11} \mathrm{Nev}-$ ertheless, healthcare advocates should take heart from previous successful traffic safety initiatives. ${ }^{12}$ Addressing the hazards posed by SUVs to pedestrians is an emerging and real traffic safety challenge in the developed world.

Ciaran Simms lecturer in mechanical engineering

Desmond O'Neill associate professor of medical gerontology

(arhc@amnch.ie)

Trinity Centre for Bioengineering and Medical Gerontology, Trinity College Dublin, Ireland

Competing interests: None declared.

7 Henary BY, Crandall J, Bhalla K, Mock CN, Roudsari BS. Child and adult pedestrian impact: the influence of vehicle type on injury severity. Ann Proc Assoc Adv Automot Med 2003;47:105-26.

8 Roudsari BS, Mock CN, Kaufman R, Grossman D, Henary BY, Crandall J. Pedestrian crashes: higher injury severity and mortality rate for light truck vehicles compared with passenger vehicles. Inj Prev 2004;10:154-8.

9 Ballesteros MF, Dischinger PC, Langenberg P. Pedestrian injuries and vehicle type in Maryland, 1995-1999. Accid Anal Prev 2004;36:73-81.

10 Breen J. Protecting pedestrians. BMJ 2002;324:1109-10.

11 Chapman S, Carter SM. "Avoid health warnings on all tobacco products for just as long as we can": a history of Australian tobacco industry efforts for just as long as we can": a history of Australian tobacco industry efforts
to avoid, delay and dilute health warnings on cigarettes. Tob Control to avoid, delay and dil

12 Breen J. Road safety advocacy. BMJ 2004;328:888-90.

\title{
Do get in touch
}

\section{Postcards from the hospital may lead to fewer episodes of self harm}

$\mathrm{E}$ ngland and Wales's recent national guideline about the early care of people who have deliberately harmed themselves ${ }^{1}$ was launched to the media with the sorry admissions that " 170,000 people a year attend emergency departments because they have self-harmed, of those an estimated 80,000 never receive a psychological assessment or follow-up even though the risk of committing suicide after self harming one or more times is 100 times greater than the average risk in the population" and "few people providing care in casualty understand why people self harm and don't know how to help them effectively." People who harm themselves also have an increased morbidity and mortality not related to suicide. ${ }^{2}$

The report by Carter and colleagues in this issue (p 805) describes one of the largest trials in self harm so far carried out. ${ }^{3}$ In a largely unselected sample of people attending the emergency department because of self poisoning in Newcastle, Australia, the researchers randomly allocated half to a simple, low cost procedure-sending them a series of postcards over the next year inviting further contact with the hospital. They found significantly fewer episodes of self harm overall, but the postcard intervention did not significantly lower the proportion of participants who went on to harm themselves again.

There is room for caution about the validity and generalisability of the findings. Firstly, a few women accounted for all of the difference in repeated episodes-and confounding may have occurred, as the groups contained unequal numbers of participants with a history of multiple episodes and hence a greater likelihood of repeated self harm during follow-up. Multiple repetitions of self harm was a planned outcome of the trial, hence stratification by number of episodes during random allocation might have been a good idea.

Furthermore, the patients in this trial had poisoned themselves rather than inflicting any other kind of harm. Although poisoning accounts for around $85 \%$ of episodes of documented self harm in the United Kingdom and elsewhere, we know of nowhere in the United Kingdom where all patients who attend an emergency department because of self poisoning are admitted to a single specialist inpatient unit, as in this Australian trial. In the United Kingdom, hospitals allow many such patients to go home after assessment in an emergency department. ${ }^{45}$ And young people frequently change addresses, making no arrangements for forwarding mail, thus follow-up may be poor in studies of postal interventions in deliberate self harm.

This trial is welcome nevertheless. Those trying to improve services for people who deliberately harm themselves are hampered when guidelines, whether from the United Kingdom, ${ }^{1}$ New Zealand, ${ }^{6}$ or elsewhere consist entirely of recommended good practice that is based on the experience of the guideline group or the opinions of expert committees. This consistently low level of evidence reflects a lack of rigorous and directly applicable clinical studies. ${ }^{7}$ The Cochrane review of interventions to decrease the repetition rate

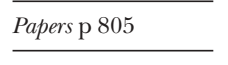

BMJ 2005;331:788-9 
after self harm found little evidence for effective interventions. ${ }^{8}$ However, the main reason is methodological: there were few trials, and many of those reviewed were too small and were undertaken with selected subgroups of patients.

Why should it be so hard to enrol people who self harm into trials? Potential participants are usually distressed, sometimes angry, and almost always in crisis, factors which greatly hamper explaining the process of randomisation, establishing clinical equipoise, and obtaining consent. Carter and colleagues used a Zelen randomisation method, in which people are randomised before consent is obtained. ${ }^{9}$ The subsequent conversation with potential research subjects is therefore far easier, as they are offered only the choice of consenting to one intervention or not. Some research ethics committees still take the view that Zelen designs are unethical, but a conventional random allocation design in Newcastle would probably have resulted in a severely underpowered trial-which is itself unethical.

Why might postcards work, and would they be useful elsewhere? People who repeatedly harm themselves often have a morbid fear of being abandoned, so they may respond to an intervention that shows that they have not been forgotten. As well, postcards may make people feel more engaged by the service. We understand engagement as the process of understanding the meaning of an episode such as self harm in the context of the person's life story and agreeing on what to do about it. Engagement at the assessment interview in hospital is a neglected area of research in psychological medicine and consequently receives little attention in clinical practice guidelines on self harm. Staff need the right attitudes and assessment skills to achieve engagement, and patients should be seen in privacy where they can sit, rather than lie down. Having services dedicated to the management of self harm, as in Newcastle, probably increases the likelihood of engagement.

This study confirms that services for people who deliberately harm themselves should measure what they do, pay attention to engagement, and offer aftercare. Even simple things should make a difference, such as systematically checking patients' contact details to ensure that the hospital has the correct telephone numbers and addresses, often those of families as well as patients. Really effective treatment may need face to face interventions, but this new evidence indicates that there may be a subgroup of people who are helped by regular contact through the mail. In future, text messages to mobile phones or emails might be tested, but, for now, snail mail seems to work.

Simon Hatcher senior lecturer in psychiatry

(s.hatcher@auckland.ac.nz)

Department of Psychological Medicine, University of Auckland,

Private Bag 92019, Auckland 1, New Zealand

David Owens senior lecturer in psychiatry

Institute of Health Sciences, University of Leeds, Leeds LS2 9LT

Competing interests: None declared.

National Institute for Clinical Excellence. The short-term physical and psychological management and secondary prevention of self-harm in primary and secondary care. London: NICE, 2004. www.nice.org.uk/ page.aspx?o = 213665 (accessed 28 Sep 2005)

2 Suominen K, Isometsa E, Ostamo A, Lonnqvist J. Level of suicidal intent predicts overall mortality and suicide after attempted suicide: a 12-year follow-up study. BMC Psychiatry 2004;4:11. www.biomedcentral.com 1471-244X/4/11 (accessed 3 Oct 2005).

3 Carter GL, Clover K, Whyte IM, Dawson AH, D'Este C. Postcards from the EDge project: randomised controlled trial of an intervention using postcards to reduce repetition of hospital treated deliberate self poisoning. BMJ 2005;331:805-7.

4 Deliberate self-harm. Effective Health Care 1998;4(6). www.york.ac.uk/inst crd/ehcb.htm (accessed 29 Aug 2005).

5 Kapur N, House A, Creed F, Feldman E, Friedman T, Guthrie E. Management of deliberate self poisoning in adults in four teaching hospitals. descriptive study. BMJ 1998;316:831-2.

6 New Zealand Guidelines Group. The assessment and management of people at risk of suicide. Wellington: NZGG, 2003. www.nzgg.org.nz/ guidelines/0005/ACF50E.pdf (accessed 31 Aug 2005).

7 Owens D. House A. General hospital services for deliberate self-harm. Haphazard clinical provision, little research, no central strategy. General Haphazard dinical Grovision, little research, no central strategy. Gener hospital services

8 Hawton K, Townsend E, Arensman E, Gunnell D, Hazell P, House A, van Heeringen K. Psychosocial and pharmacological treatments for deliberate self harm. Cochrane Database Syst Rev 1999(4): CD001764.

9 Zelen M. A new design for randomised clinical trials. $N$ Engl J Med 1979;300:1242-5.

\section{An adequate margin of excision in ductal carcinoma in situ}

\section{$2 \mathrm{~mm}$ plus radiotherapy is as good as a bigger margin}

$\mathrm{T}$ he widespread use of mammography screening has led to a change in the perceived pathology of breast cancer. The increased detection of asymptomatic disease has resulted in an increased incidence of ductal carcinoma in situ (DCIS), which now accounts for about $20 \%$ of all cases of breast cancer. In addition, the past decade has seen a change in the management of primary breast cancer, from mastectomy to breast conservation where possible. ${ }^{1}$ Clearly surgical management of DCIS poses several challenges, none more so than what should be the width of an adequate margin of resection. What is at issue is the size of the margin that ensures no residual tumour cells while minimising the deformity of the breast.

The National Surgical Adjuvant Breast and Bowel ink"-that is, a minimal margin free of disease-as a negative margin. Yet in a recent survey of 1137 radiation oncologists only $45.9 \%$ of North American respondents and 27.6\% of Europeans agreed with this definition. ${ }^{2}$ When this margin was extended to $2 \mathrm{~mm}$ over $75 \%$ of North American respondents agreed that this could be regarded as negative, while $51 \%$ from the United Kingdom continued to disagree that this margin was adequate.

A clear definition of the pathological growth behaviour of DCIS has helped to define what may be an acceptable margin of resection. Faverly et al have described a technique to define the three dimensional structure of the breast glandular tree and they have then used this to identify DCIS spread and multifocality. ${ }^{3}$ Using this technique to visualise DCIS, $90 \%$ of 